\title{
Research on the Cultivating System of E-commerce Professionals in Universities
}

Yang LIU ${ }^{1, a}$, Ze-Xuan YIN ${ }^{1, b}$, Chen ZHANG ${ }^{1, c}$,Yi-He ZHANG ${ }^{1}$, Ye WANG ${ }^{1}$,
Chun-Yan QIU ${ }^{1}$, Chi-Jun ZHANG ${ }^{1}$, Ren SONG ${ }^{2}$, Yan MA ${ }^{1, d,{ }^{*}}$ and Xiang LI ${ }^{1}$

${ }^{1}$ School of Management Science and Information Engineering, Jilin University of Finance and Economics, Changchun, 130117, China

${ }^{2}$ Information Management Center, Jilin University of Finance and Economics, Changchun, 130117, China

a email: 7923759@qq.com, bemail: 1300054033@qq.com

c2243829592@qq.com, demail: 156068349@qq.com

${ }^{*}$ Corresponding author

Keywords: Keywords: E-commerce, Innovation and Enterprise, Talent training system

\begin{abstract}
In view of the contradiction between the Social demand for talents in E-commerce and the cultivation of undergraduate talents in E-Commerce in recent years, the key to solve the phenomenon of "talent bubble" in E-Commerce is to improve the core competence of E-Commerce. Through combing the undergraduate teaching system and various links of E-Commerce major in colleges and universities, the training system of innovative and entrepreneurial talents of E-Commerce has been established, which takes employment demand as the guidance aiming to meet the needs of social and economic development and master good electronic commerce high-end knowledge and skills, and is expanded by the innovative entrepreneurship education based on the theoretical and practical teaching, driven and promoted by the construction of school-enterprise cooperation projects and the excellent project incubation by taking the laboratory construction as the foundation. In addition, the cultivation of undergraduate talents in E-Commerce in Jilin University of Finance and Economics, the only electronic commerce brand major in Jilin Province, is used as an example to deeply analyze and demonstrate the connotation of the system to constitute each module, to provide reference for the development of E-Commerce major in other colleges and universities.
\end{abstract}

\section{Introduction}

E-commerce professional higher education has been nearly 19 years of history [1]. In these 19 years, the development of e-commerce industry is in full swing, the scale of e-commerce education is gradually expanding, and more talents have been continuously output for the e-commerce industry. At present, the demand for e-commerce talents for large, medium and small enterprises is constantly expanding across the country. However, under the circumstance of strong demand for talent in the e-commerce industry, the employment rate of university e-commerce graduates is not optimistic. Currently, the demand for high-quality e-commerce application of innovative talents and the proportion of university personnel supply a serious imbalance. Only in the light of market demand can we keep pace with the times, innovate and enhance our core competence in order to keep up with the era of e-commerce. It is a problem worth our consideration that in the e-commerce industry in full swing the development of the mega-trends, it is a worth our pondering the issue what led to the undergraduate college e-commerce graduates and corporate employers demand lopsided[6].

\section{Existing Problems of E-Commerce Talent Training}

At present, there are many problems in the cultivation of e-commerce professionals in China. Many 
documents analyze the causes of existing problems from the perspective of e-commerce undergraduate talents cultivation. Many documents analyze the causes of existing problems from the perspective of e-commerce undergraduate talents cultivation. Such as talent training objectives are not clear, E-commerce professional school time is short, unreasonable teacher team structure, immature teaching experience. From the aspect of the structure of teaching curriculum, e-commerce is an interdisciplinary subject that integrates many disciplines. There is no systematic organic integration between curriculum and curriculum, and the system of curriculum structure is not set up properly[2].

Wu Qinglie is the head of the department of Southeast University pointed out:" E-commerce professionals different from other major core competencies, mainly reflected in the innovative concept of e-commerce applications based on the analysis and design capabilities."[4]How to improve the analysis and design ability of e-commerce applications innovative concepts in e-commerce undergraduate talents cultivation and improve the core competitiveness of e-commerce profession, it is critical to establish a complete and reasonable e-commerce talent cultivation system.

\section{College e - Commerce Professional Innovation and Entrepreneurship Training System.}

E-commerce professional innovation and entrepreneurship training system in colleges and universities is to cultivate "innovation and entrepreneurship" as the goal, the innovation and entrepreneurship into the e-commerce talent training process and is the reform of e-commerce professional theory teaching curriculum system, practice teaching curriculum system and teaching methods. At the same time, to enhance student innovation and entrepreneurship practice as the core, vigorously promote the laboratory construction, campus training base construction, school-enterprise cooperation training base construction [5], as well as innovation and entrepreneurship incubation base, in order to build college e-commerce innovation and entrepreneurship Talent training system.As shown in Figure 1.

\section{Jilin University of Finance e-Commerce Professional Innovation and Entrepreneurship Training System}

Jilin University of Finance and Commerce approved the establishment of e-commerce in 2002, formal enrollment in 2003, and approved the only e-commerce brand major of Jilin Province in 2015. Through 14 years of continuous construction and development, some achievements have been made in the cultivation of e-commerce talents in local undergraduate colleges and universities.

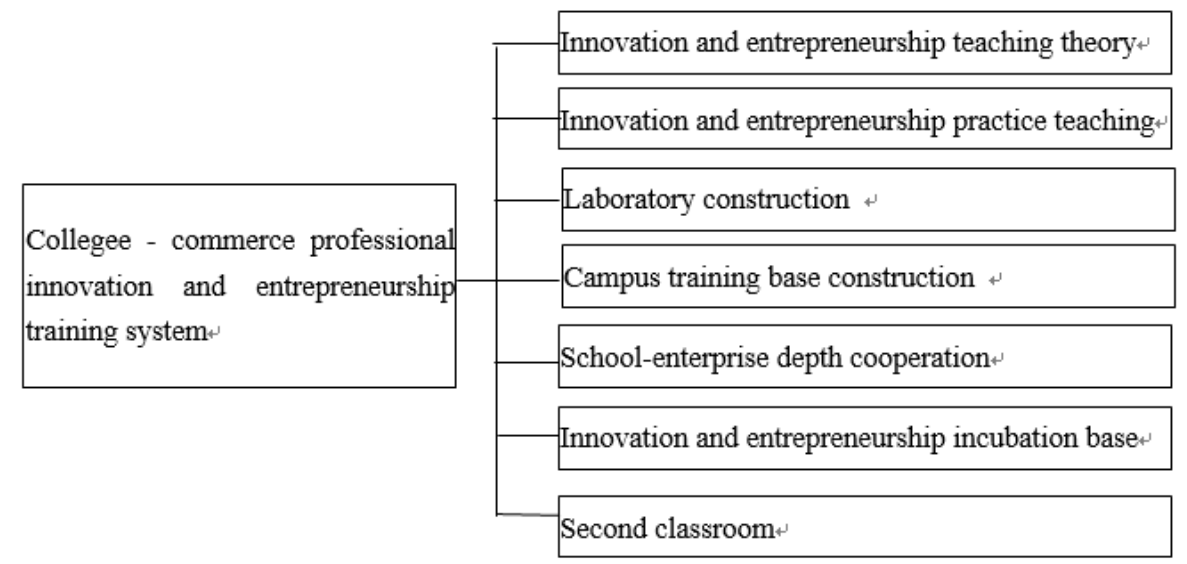

Figure 1: E-commerce professional innovation and entrepreneurship training system theory model

\footnotetext{
Innovative Entrepreneurship Education and Diversification Systematic Theoretical Knowledge Combined
} 
E-commerce professionals training program, the teaching plan is divided into theoretical teaching system and practice teaching system. The theoretical teaching system consists of five modules: general basic course, basic subject course, major trunk course, professional limited course and optional course in the whole school. The first stage is the basic education stage, the two basic platforms for general knowledge and basic subjects are set up. Basic courses are opened up according to disciplines and a solid foundation of basic disciplines is laid so as to lay a solid foundation for future professional choices of students. The second stage is a professional learning stage. Selected professional course content, after completing the professional backbone module learning, flexible setting of professional limit selection of curriculum modules, to achieve the students according to personal interests of the professional direction of the course diversion [7]. The third stage is the ability to expand stage, innovation and entrepreneurship courses, focusing on improving students' comprehensive ability and broaden their knowledge. In the education system, we should integrate innovation and entrepreneurship education, cultivate students 'innovative awareness and entrepreneurial ability, and constantly improve students' ability to master deep basic theories while strengthening students' innovation and entrepreneurial awareness and practical application ability. Theoretical teaching module shown in Figure 2.

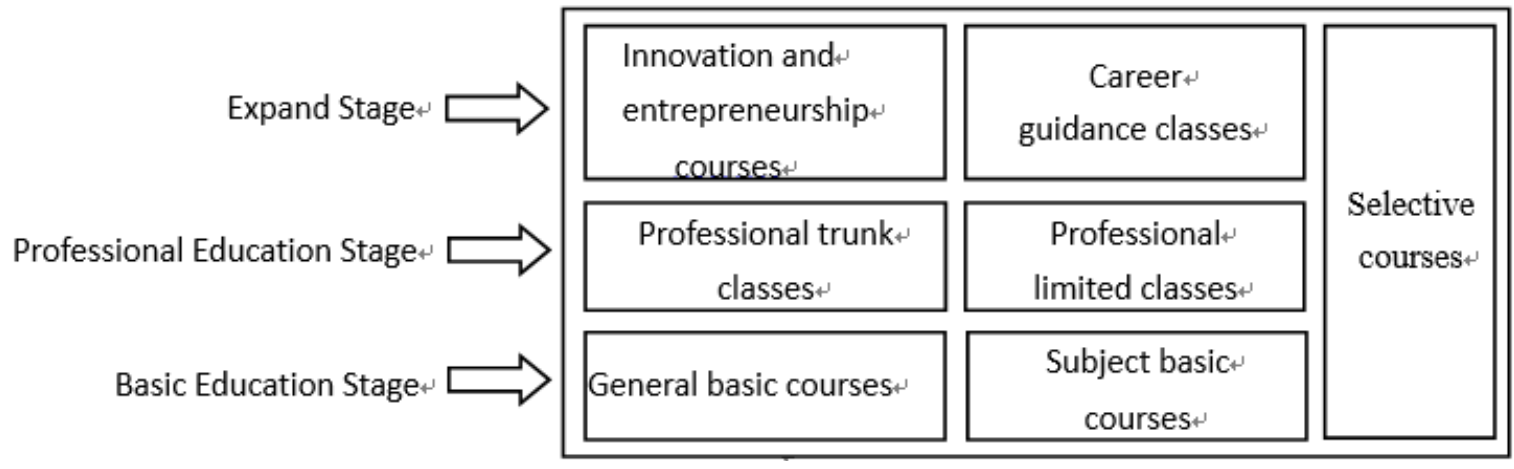

Figure 2: Theoretical teaching model

\section{Reconstruction of Practical Teaching Modules, the Implementation of Innovative Entrepreneurship Teaching Mode}

Innovation and entrepreneurship practice teaching module is a teaching module focused on building e-commerce, and the curriculum should account for 25\%.As shown in Figure 3, practical teaching mode includes basic practice, professional practice and comprehensive practice .At the same time, combining with theoretical teaching. Through basic practice, students can improve their basic skills in cognitive social, professional, and teamwork and lay the groundwork for professional learning; through professional practice .Through professional practice, students' professional knowledge can be deepened. Training students to master the basic professional skills and methods can promote students' scientific thinking, innovative awareness and ability to innovate. Through comprehensive practice, students are trained to comprehensively use their knowledge to analyze and solve problems, and to improve their ability to quickly adapt to the job, so as to cultivate students' overall accomplishment. 


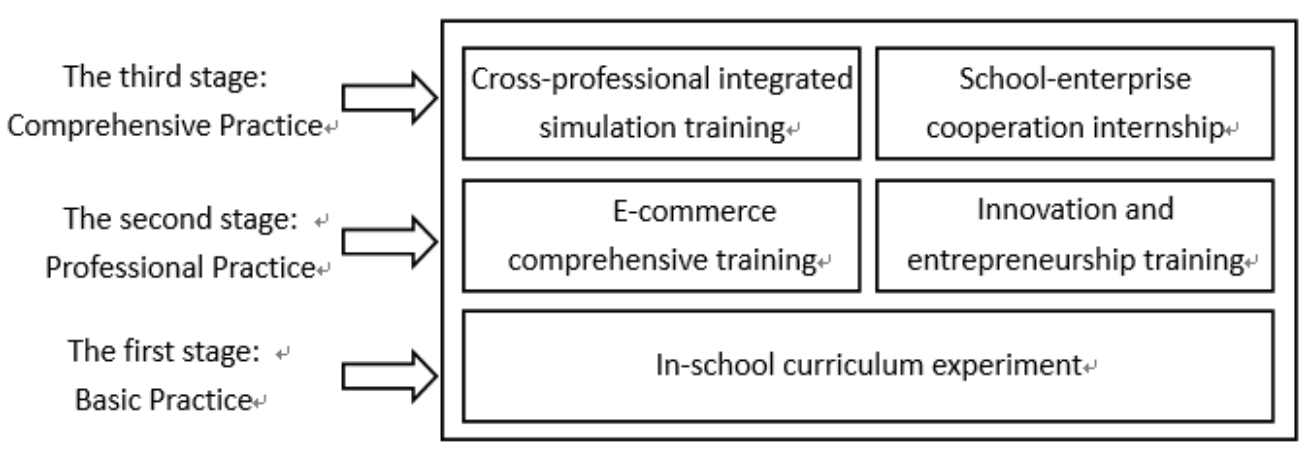

Figure3: Practical teaching mode

\section{Laboratory Construction as the Foundation for the Training System Escort}

As an important part of teaching resources of higher education, laboratories bear the heavy responsibility of developing professional theoretical practice and knowledge development, providing students with a relatively open environment and a place for innovative practice[8]. It is the source of knowledge innovation and scientific and technological personnel training base, but also an important symbol of the university running conditions and personnel training platform evaluation. The E-commerce professionals of Jilin University of Finance and Economics intends to build multi-type laboratories. Enhancing students' cognition of the actual operation process of e-commerce enterprises and enhance the ability of applying theoretical knowledge to practical operation in the simulation environment. At present, Jilin University of Finance and Economics has gained many provincial Internet laboratories such as Jilin Province Key Laboratory of Internet Finance, Logistics and Supply Chain Management Laboratory, E-Commerce and Internet Finance Laboratory, Intelligent Finance and Decision Optimization Laboratory and Economic Information Management Laboratory. At the same time, the college is building a professional e-commerce brand, successfully joined the "National University E-Commerce and E-Government Joint Laboratory" in 2014. Established in the province only the Ministry of Education National University e-commerce and e-government Joint Laboratory Jilin University of Finance and Economics branch, and Achieved with the joint laboratory members, including more than 40 major domestic universities and enterprises to share resources and expand college resources.

\section{The Establishment of School Training Base, Three Platforms to Improve the Practice Teaching System}

Relying on the construction of laboratory training base on the laboratory building, mainly to the three major platforms. Through practical training, students can enhance their teamwork spirit, cultivate scientific thinking methods, improve practical ability, and achieve teaching, research and social services[9].

Jilin University of Finance e-commerce professional to the existing national university e-commerce and e-government joint laboratory (Jilin University of Finance and Economics branch), logistics industry economy and intelligent logistics provincial key laboratory as a platform for many activities, such as building e-commerce Training platform, the purchase of e-commerce simulation software, realizing intelligent data analysis, strengthen the practical teaching of business intelligence courses, and finally achieved a set of teaching and research as one integrated platform. Entrepreneurial projects as a carrier to entrepreneurial team for the organization of college students in innovation and entrepreneurship training platform, entrepreneurial education will teach the entrepreneurial process, business planning, entrepreneurial tools, entrepreneurial methods and so on in a specific project simulation. Through the simulation of the entrepreneurial process in economic and social environment, and through the collaboration of team members and team confrontation experience the entire entrepreneurial process. Through the cognition of the entrepreneurial environment, the students' innovation and entrepreneurship training platform guides 
students to recognize the current business and industry environment, understand the business opportunities, grasp the risks of entrepreneurship, master the process of business model development, and design strategies and techniques. And through practical training to improve students 'awareness of the market and control, cultivate students' innovative thinking and innovative awareness, improve their entrepreneurial qualities, which play a positive guiding role in the employment of students.

To realize the cultivation of diversified compound-type e-commerce talents, the cross-disciplinary comprehensive platform training expanding in the e-commerce profession. The cross-professional comprehensive simulation training platform is a multidisciplinary platform, which based on the reality business community perspective. Through the simulation of business, services and manufacturing industry, the fictitious economic market with production, sales, supply, demand, competition are interlaced and interdependent .The simulate economic environment has great help to cultivate students' independent entrepreneurial innovation ability. At the same time, it greatly improves their professional abilities, teamwork, cooperation and communication, and business decisions. Therefore, cross-disciplinary comprehensive simulation training platform plays an important role in cultivating inter-professional talents and innovative talents.

\section{Enrich the Second Class, to Help Students Develop in An all-Round Way}

Jilin University of Finance and Economics regularly launches the "Innovation and Entrepreneurship Salon", organizes college students' innovation and entrepreneurship projects, shares ideas on innovation and entrepreneurship, exchanges innovation and entrepreneurship experience, and promotes innovation and entrepreneurship skills. At the same time actively encourage students to participate in e-commerce innovation and entrepreneurship discipline competition, to promote learning to race to promote education. Enrich the second class, to help students develop in an all-round way

\section{Conclusions}

At present, the college e-commerce professional innovation and entrepreneurship training system is still in the process of continuous exploration, and still needs further improvement. In the process of continuous exploration, we will actively introduce the elements of "three innovations" in e-commerce education to integrate the spirit of "three innovations" and education. While continuously improving our students 'mastery of profound basic theories, we should enhance our ability to cultivate students' awareness of "creating the three challenges" and their practical application ability, reform the curriculum system and improve practical teaching so as to bring "three innovations" education through to innovation and entrepreneurship professionals in e-commerce The whole process of training.

\section{Acknowledgement}

This paper was the final research result of The Teaching Reform Research of Higher Education in Jilin Province “E-Commerce Major 'the Three Innovations Talents' Training Mode Research”. This research was supported by the Higher Education Institute of Jilin Province under grant No. JGJX2017D105 and No. JGJX2016D91, the support project of Philosophy and Social Sciences Planning Project of Changchun under grant No. CSKT2017ZX-0017, the support project of Jilin Department of Education "Thirteen Five" science and technology under grant No.JJKH20170122KJ, the support project of Jilin Province Education Science "Thirteen Five" Planning under grant No. GH170336, the support project of Jilin Province Education Science " Twelfth Five" Planning under grant No. GH150286.

\section{References}

[1]QiL, LiZ, Li-fangP. Reflection on Training Model of Interdisciplinary E-commerce 
Talents ,J.Economy Management, 2007, (14):58-63.

[2]Yang L, Zhi W, Chun-yan Q.Exploration of "three creation" practice teaching system for electronic commerce major in Colleges and Universities ,J.Modern Economic Information, 2017,(01):420-421.

[3]Qing-lie W. Misunderstandings and Professional Development of E - commerce Talent Training in China,J. China University Teaching. 2015,(02):37-41.

[4]Rui-jun G,Yu-liang Z, Juan Y. Training system of "three Innovations" practice Teaching for Electronic Commerce Specialty,J. Research and Exploration in Laboratory. 2012,(01):174-177.

[5] HuT, ShenL. The Enlightenment of Foreign Innovation and Entrepreneurship Education to Our Universities,J. China University Teaching. 2013,(02):91-94.

[6]He-ping X. Guided by Innovation and Entrepreneurship Education to Deepen the Reform of Education and Teaching,J. Journal of China Higher Education Research2017.(03):1-5.

[7]HuaX,Yan-fang W. Exploration of Laboratory Open Mode with Innovative Talents as the Core ,J. Journal of Experimental Technology and Management. 2016.(01):9-12.

[8]Yan M,Yang L. Study on the countermeasures of the cultivation of compound talents in college e-commerce , J.Journal of Information construction. 2016,(04):176-177. 